\title{
Discursos, violências e sensibilizações anti- cyberbullying: nós, os Outros e as virtualidades reais
}

Alexandre Luiz Polizel alexandre polizel@hotmail.com 0000-0001-6397-306X Universidade Estadual de Maringá - Brasil

Nara Alves Mendes nara-sl@hotmail.com 0000-0003-2193-661X Universidade Estadual de Maringá - Brasil

Fabiana Aparecida de Carvalho facarvalho@uem.br 0000-0002-6746-420 Universidade Estadual de Maringá - Brasil

\section{RESUMO}

O presente trabalho apresenta dinâmicas, discussões e reflexões destacadas da modalidade Estágio Não Convencional, realizada durante o Estágio Supervisionado para Docência em Biologia, principalmente no que tange a uma sensibilização anti-bullying ocorrida na oficina "Cyberbullying: todxs somos violentadxs?". A atividade deu-se com duas turmas de segundo ano do ensino médio de uma escola central do município de Maringá (PR). Cada oficina teve duração de quatro horas aula envolvendo a problematização de postagens na rede social facebook, em sítios ou páginas da web classificadas como de humor, bem como a elaboração de personagens e suas histórias a fim de se discutir os problemas relativos ao bullying e de se colocar no lugar do Outro. Entre problematizações e narrativas dos alunos, propusemos, então, (re) pensar os discursos que os circundam na escola, seus significados, efeitos e atravessamentos na construção, modos de ser e estar no mundo.

PALAVRAS-CHAVE: Cyberbullying. Subjetividades. Estágio Supervisionado em Biologia. Sensibilização. 
Nosso ponto de partida: de onde falamos como licenciandos em Ciências Biológicas e nosso desdobramento em uma modalidade de Estágio Supervisionado

O estágio supervisionado tem se configurado como espaço-tempo de formação, preparo e discussão da docência e das condições de produção dos saberes escolares. Convencionalmente, as abordagens formativas dividem-se em: a) ambientação e observação: momentos em que se tomam os contatos com a realidade administrativa e pedagógica das escolas, cria-se um olhar atento para as dinâmicas de sala de aula e se observam as interações professor-aluno ao se trabalhar os conhecimentos específicos da disciplina; b) participação em sala: quando se intervém em dinâmicas e eventuais preparos de aula junto ao docente regente; e c) regência propriamente dita: quando o estagiário tem a oportunidade de se relacionar com alunos, desenvolver metodologias e encaminhamentos e ministrar o ensino dos conteúdos escolares em suas táticas e exercícios profissionais. "Enquanto campo de conhecimento, o estágio se produz na interação dos cursos de formação com o campo social no qual se desenvolvem as práticas educativas" (LIMA; PIMENTA, 2006, p. 06), assim, ele é também um momento na formação inicial docente onde questões sociais, culturais e mesmo subjetivas se misturam aos saberes e conhecimentos específicos da área de conhecimento e expandem as interações em sala de aula.

Entretanto, muitos desdobramentos do estágio supervisionado têm dado enfoque apenas à instrumentalização técnica. As dinâmicas, via de regra, têm sido circunscritas pela aplicação de metodologias e encaminhamentos didáticos, reforçando a prescrição de conteúdos no ensinar e no aprender. Nesta ênfase técnica, as habilidades dos licenciados nem sempre são suficientes para a resolução de problemas e para o encaminhamento de questões diferenciadas e culturais que se decantam em sala de aula. Quando pensamos no âmbito da formação em Ciências Biológicas, deparamo-nos também com o caráter específico da disciplina e com a necessidade de ministrar conteúdos que nem sempre são afeitos os alunos na escola.

Para fugir dessa abordagem, é aberto na disciplina de "Estágio de docência", do curso de Ciências Biológicas da Universidade Estadual de Maringá, um intervalo não convencional, no qual se realizam oficinas didáticas com temas transversais, cotidianos, com turmas mistas e sob enfoques metodológicos diferenciados. Nos últimos 3 anos, os licenciados passaram por interações com o conhecimento biológico em turmas de cursos técnicos voltados à formação docente (magistério), de salas de habilidades especiais (alunos com altas habilidades e superdotação) e de alunos de escolas no campo (ensino dentro do Movimento Sem Terra - MST). Essa dinâmica tem sido producente para proporcionar ao futuro professor a visão de diferentes contextos e espaços pedagógicos, como também das circunstâncias onde a Biologia é ensinada diferentemente da sala de aula e se intersecta com valores e atitudes.

No ano de 2015, durante o intervalo de estágio numa escola central da cidade de Maringá, e convivendo com alunos e seus interesses, pudemos perceber que assuntos como corpo e corporalidade, sexualidade, identificação ou aversão ao outro, mundo cibernético, acesso às redes sociais adensam a sala de aula e requerem o cruzamento dos conceitos com outras 'biologias' e vivências. 
Esses assuntos são tencionados nos corredores e nas aulas com a presença de cartazes, a evocação de certas práticas e comportamentos, as condutas impostas aos alunos e professores quando a escola aciona regras e normas que atravessam os corpos dos alunos. Práticas negativas, como o bullying direto ou indireto, nem sempre são percebidas como tal e acabam se naturalizando nos espaços de vivência e nas relações com a apreensão dos conteúdos em cada disciplina.

Em temporalidades onde as informações se volatizam rápido demais e os discursos são tensionados em redes de significações, conhecer o foco da interação social e cultural dos saberes é um campo profícuo para se problematizar os significados que constantemente se resignificam e geram efeitos constitutivos nas pessoas. Nestes tempos, o conhecimento científico, hierarquizado como verdade absoluta, impõe uma formação mais técnica para os licenciandos. Entretanto, na realidade escolar, este não será o único saber a circular na escola; os saberes culturais adentram as aulas e expandem o conhecimento biológico, expondo a própria necessidade dos alunos e questões que não se encontram nos currículos hegemônicos e oficializados.

[...] a própria ciência biológica é tomada como uma instância cultural, já que está implicada na instituição de significados e de identidades sociais. Tal entendimento permite que qualquer artefato cultural seja passível de ser um material didático para nossas aulas, menos para apontar os seus 'erros' ou as suas 'distorções' (foco que presumiria haver um lugar mais legítimo e mais apropriado para a enunciação científica e esse não seria o espaço da mídia), mas para entender, efetiva e minimamente, o que eles nos ensinam sobre biologia, sobre corpo, sobre beleza, sobre saúde, sobre 'ser homem', sobre natureza, sobre genética, sobre o DNA, sobre os seres vivos etc. Em resumo, podemos dizer que inúmeras práticas e instâncias sociais estão implicadas na produção discursiva da biologia e interessaria para nós, praticantes de estudos culturais, entendermos os diferentes modos através dos quais ela é instituída (GUIMARÃES; SILVA, 2009, p. 36).

Conforme destacado acima, inúmeras práticas e instâncias sociais estão implicadas na discursividade escolar e nas apropriações do conhecimento biológico. Dentro desse pensamento, o entendimento de currículo não é nunca neutro, pois todos os currículos são atravessados constantemente por questões de etnia, gênero, classe e regionalidades (SANTOMÉ, 2013), como também pelos demais conflitos sociais e pelos interesses que moldam a comunidade escolar.

Embora nas escolas e no estágio, convencionalmente, desdobram-se os aspectos curriculares que servem para a normatização dos corpos e para a hegemonia dos conteúdos veiculados por livros didáticos, apostilas, processos avaliativos, nós, como professores em formação, fomos instigados a pensar um direcionamento contra hegemônico e a dimensionar o estágio supervisionado, tanto a regência, quanto as atividades de oficina, para temas e encaminhamentos que teriam mais relevância para os alunos e se intesectassem com questões de gênero, etnia, classe, corpo e pertencimentos identitários e culturais.

Durante a realização do Estágio não Convencional, tivemos a oportunidade de escolher a temática que abordaríamos com os alunos da escola campo.

Tradicionalmente, quando se falam em oficinas, alguns temas e discussões já estão evidenciados e aguardados como tradição escolar: infecções sexualmente transmissíveis (ISTs), drogas e prevenção, animais peçonhentos, reciclagem e lixo, entre outros, são determinados no campo do estágio como 
temas escolhidos e por professores ou pela direção escolar com certa recorrência. Entretanto, nas intervenções pedagógicas diversas, principalmente aquelas que visam alternativas diferenciadas dos encaminhamentos didáticos tradicionais, tais temas são, em boa parte das vezes, encaminhados de forma prescritiva, com ênfase em normas de compartamento e de conduta, ou, ainda, postos como uma simples apresentação de informações biológicas. Estas, por efeito, convertem-se em ilustrações ou apêndices do que já é dito em sala de aula, ou, ainda, em explanações que pautam os assuntos pela tom da curiosidade e do exotismo e não pela significação junto aos alunos, considerando seus interesses e motivações.

Durante o preparo das atividades do estágio, colocamo-nos a pensar em quais seriam os deslocamentos das redes de significação sobre corpo, ou seja, sobre qual significado é dado ao corpo no contexto dos discursos científicos e sociais; sobre respeito e sobre ser e estar no mundo e na escola, e em como estes pensamentos são (re)configurados e atravessados pela cultura. Esta indagação levou-nos a um questionamento: Que (in)formação gostaríamos de possibilitar aos nossos alunos e que temas seriam a eles mais afeitos? Visando alguns discursos que circulam dentro e fora da escola, decidimos por trabalhar a temática do bullying como possibilidade de também problematizar as atitudes e os usos do (cyber)espaço nas inter-relações desse no âmbito escolar. Isto posto, decidimos por nos desdobrar junto à problemática: o lugar d'Outro - somos, nós, cometedores de violências e disseminadores de discursos que inscrevem marcas nos corpos?

Sabemos que a escola pode funcionar como uma instituição social disciplinatória e de controle (FOUCAULT, 2014a), e que, em sua regimentação atual, ela normatiza e controla corpos e mentes, voltando-os à produtividade no estudo. Quando se fala no uso de tecnologias dentro de sala de aula, observamos certo controle como, por exemplo, a proibição de aparelhos/equipamentos eletrônicos durante o horário de permanência (BRASIL, 2014), permitindo apenas o uso para fins pedagógicos e relacionados à aplicação dos conteúdos disciplinares. A internet, muitas vezes, tem sido deixada fora dos muros escolares. Neste contexto de proibição e controle, careceu perguntar: em quais momentos as 'informáticas' estão presentes na escola? E as discussões sobre o (cyber)espaço? Ou mesmo as violências que são apreendidas nesses meios e reproduzidas nos espaços de convívio e de relação? A Internet realmente se escolariza junto às demandas pedagógicas e dos conteúdos específicos de cada disciplina? Qual seu espaço dentro da escola? Quais inscrições e marcas ela deixa nos corpos dos alunos?

Apostamos em trabalhar com o tema do bullying no (cyber)espaço na prática de estágio não convencional, principalmente com o intuito de também propiciar a descentralização das identidades tidas como evidentes ou hegemônicas, entendendo-as como fragmentadas, fluidas e componentes da diversidade escolar (SILVA, 2011). Compreendemos também que a Biologia, como uma desencadeadora de processos de reconhecimento e afirmação de identidades e corpos, não se encontra sozinha nas produções de significados sobre o mundo, mas antes é substrato para a composição de diferentes produções narrativas que deslizam sobre outros significados e contextos culturais (SANTOS, 2000). Logo, no corpo disciplinar da Biologia e nas narrativas por ela produzidas passam a vigorar regimes de verdade e discursos estruturados por 
discursos dominantes. Tal efeito pode naturalizar aspectos que não são naturais e atravessar os corpos escolares normatizando suas condutas (FOUCAULT, 1988) e naturalizando certas ações que levam ao desrespeito.

Colocamo-nos a pensar, durante nossa formação inicial, sob os discursos que nos circundam e permeiam nosso papel como professores para (re)pensar e (re)negociar nossas representações sobre a escola. Assim sendo, o planejamento das dinâmicas da oficina também se voltou para uma ótica de planejamentos culturais junto à nossa prática (GUIMARÃES; SILVA, 2009). Diante do exposto, apresentamos o relato de nossas experiências e reflexões durante o Estágio Supervisionado para Docência em Biologia, principalmente a partir das discussões ministradas na oficina: "(Cyber)bullying: todxs somos violentadxs?".

\section{Discursividade no (Cyber)espaço: princípios norteadores da proposição da oficina}

Ao se pensar os (cyber)espaços se é preciso compreender como tal âmbito permite a veiculação de discursos, a (re)negociação de significados, a luta social e a reiteração de condutas que modulam modos de ser e a circulação de atitudes baseadas na violência.

Com o 'boom' da internet, alguns discursos funcionam como dispositivos que determinam e ou legislam sobre os sistemas de exclusão e segregação, como exemplo: palavras ofensivas, violência direcionada às minorias sociais, afrontas e chacotas. Nas redes sociais, diferentes culturas passam a se comunicar entre si, rompendo diferenciações do espaço de convívio as quais se interligam (FREIRE et al., 2013) e/ou se segregam. Neste tocante, Levy (1999) pondera o (cyber)espaço como local de comunicação que rompe barreiras físicas e de temporalidades, permitindo a exploração de potencialidades ao se hibridizar os planos políticos, econômicos, culturais e humanos. Este espaço configura o que chama de "interconexão de mensagens", a produção do texto escrito carrega consigo múltiplos sentidos e interpretações. Significados estes que são renovados continuamente a cada revisita ao discurso. O significado não é estático, e assim nos possibilita instigar os estudantes a revisitar estas representações e (re)pensálas, ou seja, jogar ou interagir com essas significações a fim de ver o outro e a si mesmo.

Com as propagações discursivas facilitadas, a intimidação presencial é transportada ao (cyber)espaço (FREIRE et al., 2013); o bullying produzido como dispositivo na escola é também translocado junto a essas tecnologias e, muitas vezes, mesclados com discursos midiáticos e fragmentos de discursos científicos que se servem a um determinismo ou a apelações que vão diminuir as diferenças. Barros (2014) afirma que o (cyber)bullying e seus derivados devem ser considerados formas históricas produzidas socialmente, de modo que estes encrustam-se nos discursos que constituem o experiênciar do sujeito. $\mathrm{O}$ autor ressalta ainda que a intervenção de tal dispositivo desloca as discursividades englobadas nas naturalizações e despolitizações da violência escolar e extra muro. Assim, o instrumental (chacotas, piadas, comentários violentos, uso outro) do (cyber)bullying sustenta e reitera os discursos escolhidos como 
verdadeiros através de uma exaustiva repetição de palavras ou mesmo de silenciamentos.

Estes instrumentos, que se constituem em violências simbólicas, psicológicas, podendo até chegar ao nível das físicas e corpóreas, são ordenados cada vez mais como produções abarcadas por diversas esferas: culturais, sociais, econômicas, políticas (BARROS, 2014) e que possuem multicasualidade (ROCHA, 2010). Enquanto as construções de um mundo interconectado intersectam as organizações culturais, as questões passam a tocar profundamente a subjetividade (PEREIRA, 2015). Os regimes de verdades que precarizam os corpos se intensificam, na medida em que na internet as normas, as regras e as moralidades são fraturadas (PRADAS, 2006). Quem vigia ou pune nesta rede de (re)produção discursiva? No mundo virtual, a manifestação mais livre de se expressar leva possibilidades de violências, mas, também, à produção de novas subjetividades e formas de ser e estar no mundo (ROSA, 2011).

Atentar-se a estas questões permite não apenas mapear atores e práticas no qual o processo de (cyber)bullying se organiza, mas, também, problematizar as lógicas do saber e como as produções discursivas são atravessadas e permeiam o âmbito escolar (TUDIN, 2008). A possibilidade de dialogar com compreensões de vítima e agressor faz com que tal espaço de discussão seja também um espaço de diagnóstico. Esta diagnose permite não apenas focar percepções, mas de compreender que os discursos produzidos no (cyber)espaço atravessam também o espaço físico e também atuam na produção dos modos de ser e estar (FREIRE et al., 2013).

Delineando a oficina: espaço de acontecimento e discussão além da Biologia curricular

As discussões e seus efeitos deram-se durante a participação do Estágio não convencional para o ensino de Biologia, realizado no formato de oficinas, com duas turmas de segundo ano do Ensino Médio de uma Escola Pública de Maringá (PR), em dias distintos, com quatro horas aula cada e perfazendo um público total de 40 estudantes.

Frente às turmas disponibilizadas e a liberdade na escolha da temática, debruçamo-nos na escolha da violência em redes sob dois aspectos: a) levantar discussões sociais em corpos conceituais da Biologia e suas intersecções com preconceitos étnico/raciais, de gênero, regionalidades e orientação sexual de modo a demonstrar aos estudantes que estas questões também poderiam ser discutidas independentes da disciplina curricular; b) pensar no advento da internet como instrumento de comunicação que modificou algumas dinâmicas sociais, criando uma (cyber)cultura que incide nos processos identitários e nos discursos escolares.

A dinâmica que direcionava as discussões consistia na exibição de fotos retiradas de páginas da rede social Facebook, como: Bananal ${ }^{1}$, Anti-modinha $2.0^{2}$ 
violências simbólicas e fomentam atividades desrespeitosas para com as pessoas. O número de acessos e a características das páginas foram critérios levantados pelos licenciandos para seleção das imagens e dos conteúdos. A Figura 1, por exemplo, elucida as imagens analisadas nas oficinas, evidenciando um caso claro de racismo tanto nos comentários quanto na própria disponibilidade virtual da página que se auto intitula como de 'humor ácido'.

As críticas às páginas de humor, muitas vezes, manifestam-se como correntes de denúncias à própria rede Facebook, entretanto, dificilmente saem do ar, ou, ainda quando saem, podem ser recriadas como outros nomes e conteúdos. Tem-se, ao nível do senso comum e do desconhecimento, a impressão de que a internet seja um território sem lei, contudo o Supremo Tribunal de Justiça do Brasil ressalta a possibilidade da utilização do Código Penal, do Código Civil e de legislações especificas, como o Marco Cívil para a Internet, que vêm sendo estruturadas para crimes cibernéticos (BRASIL, 2009) e com o intuito de regulamentar os acessos para se evitar ultrajes.

Figura 1 - Imagem retirada de página do facebook - Injúria racial

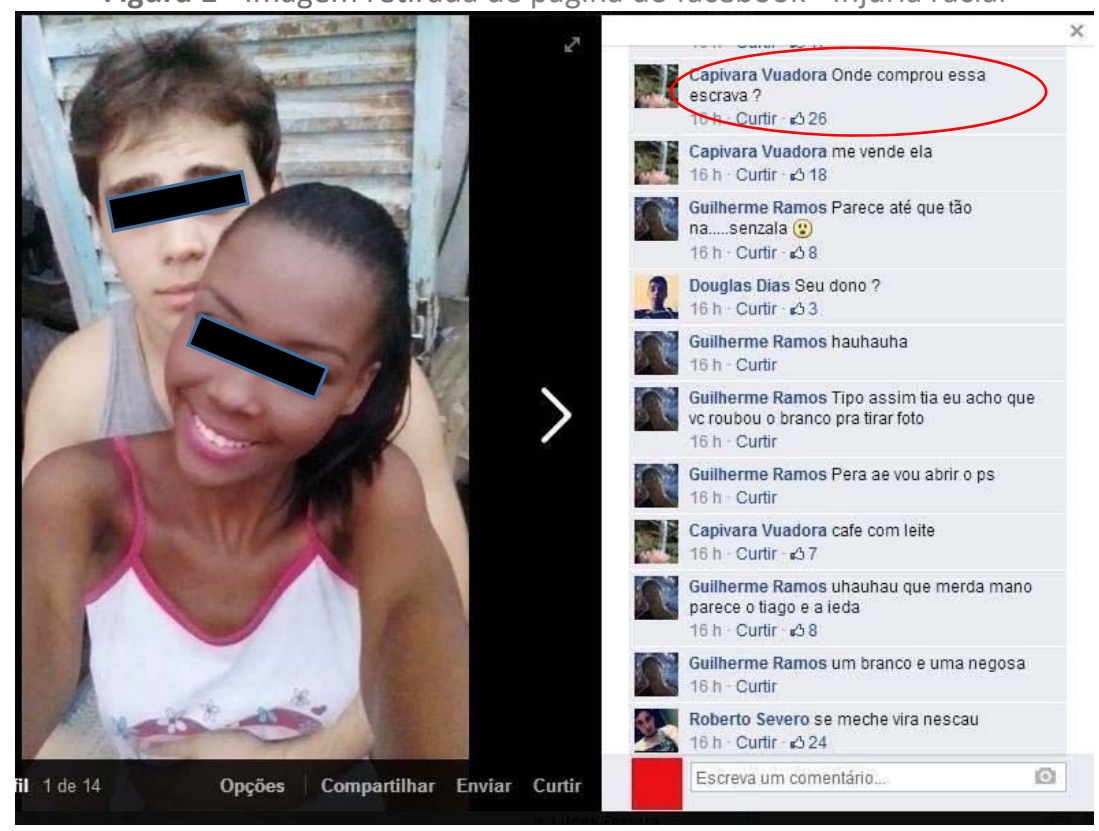

Durante a projeção das imagens foi solicitado aos estudantes que pontuassem: a) se os discursos carreavam alguma violência?; b) se existe alguma semelhança entre as vítimas e os agressores, no que tange ao discurso utilizado e as características de ambos?; c) se esses discursos violentos transitam também pelo ambiente escolar? Estas questões nortearam todas as discussões seguintes.

Em um segundo momento, como proposta de dinâmica, os estudantes foram divididos em 6 grupos, sendo sorteados para cada um deles cinco marcadores identitários, a saber: mulher, transgênero, haitiano, nordestino, lésbica e homossexual; também foram sorteadas cinco frases com as quais estes personagens se esbarrariam em rede social: a) Ela ou ele fala e escreve assim por que não estudou; b) Elas ou eles vêm de lá para cá trazer doença; c) É assim por falta de apanhar; d) Elas ou eles vêm de lá para cá roubar os nossos empregos; e) 
Tinha que ser mulher. Após o sorteio das características, os estudantes deveriam criar uma situação ou personagem ficcional, ao qual poderiam se posicionar ou não quanto às frases com que se depararam nas redes sociais (FIGURA 2).

Tal dinâmica mesclou-se entre as metodologias de Storytelling (ST) e RolePlaying Game (RPG) (ARAUJO; RAMALHO, 2009; GUIMARÃES; SIMÃO 2007), ou seja, perfizeram um mix de conotações de histórias e jogos de representações nos quais, ao narrar o outro, a expressão da subjetividade e o narrar a si mesmo encontram-se evidenciadas. Com o aspecto de RPG de mesa e ST, o histórico do personagem mostrava-se aberto para narrar seu passado, presente e se incentiva o jogador a ser o personagem, a conhecer a si e ao outro.

Este histórico foi construído de maneira livre, norteado pelas características sorteadas e os estudantes esboçaram a história e construíram o personagem utilizando folha sulfite e discussões dentro de seu grupo. Estas anotações poderiam ser utilizadas durante a apresentação, mas de preferência, fazendo uma performance e buscando se colocar no lugar do personagem para refletir se "Pensamos n'Outro? Conseguimos enxergar, ou nos aproximar da sua visão, sob sua lente?".

Figura 2 - Discussão durante a oficina
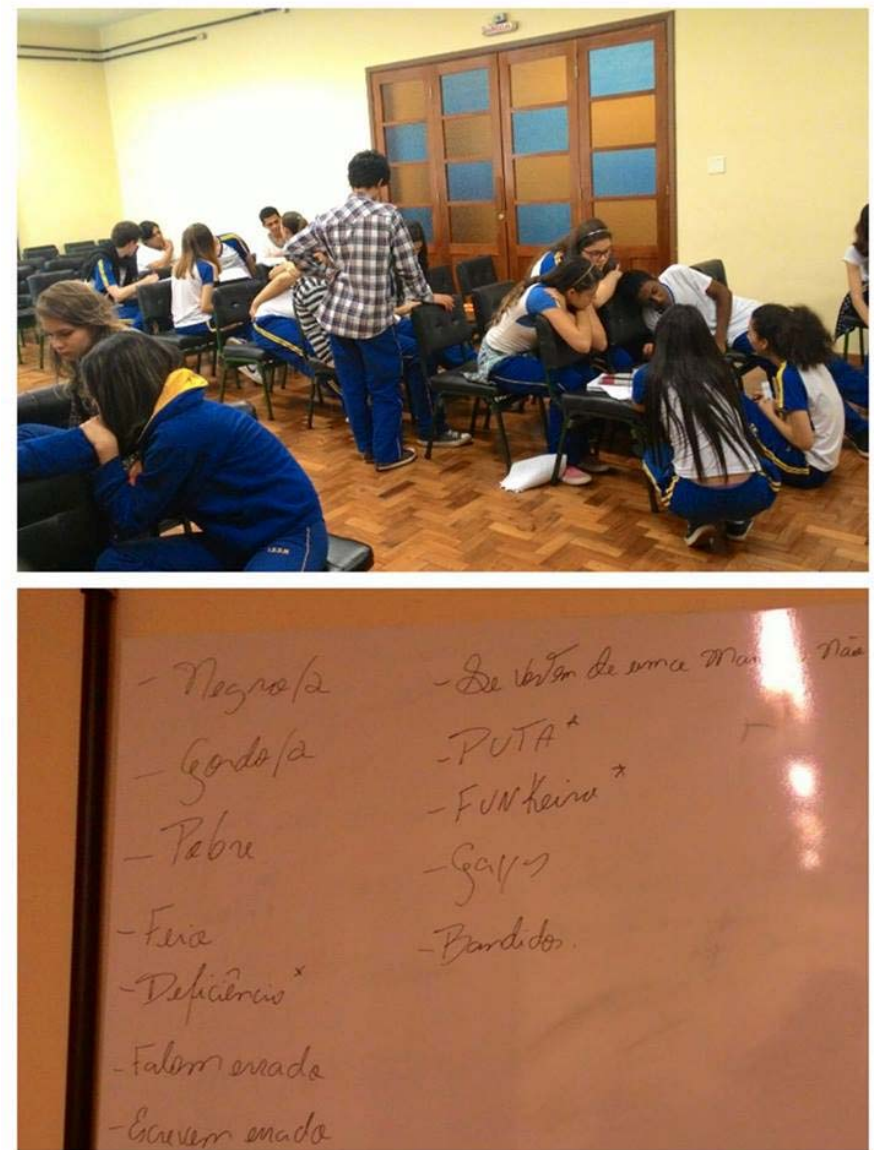

(Fonte: Acervo pessoal dos autores) 
Durante a apresentação da temática discutida e das regras que guiaram a dinâmica, os estudantes relataram que conheciam as páginas de onde as imagens foram retiradas de modo que as suas opiniões se dividiam entre considerarem as páginas como conteúdo de humor livre de bullying e como páginas de mau gosto. Tais ponderações permitiram-nos discutir de onde estes discursos surgiram e em quais identificações tocam para que alguns os considerassem engraçados e outros violentos. Aportamo-nos em Foucault (2014a, 2014b), ao levantar discussões sobre a produção de discursos e significados e como esses são controlados sob a regência de um sistema disciplinatório e de controle, compreendendo que a produção de discurso levava em consideração não apenas um local e temporalidade de quem o (re)produzia, mas também os signos que o indivíduo carreava consigo, legitimando-o ou não em relação à sua utilização.

Observamos que dentro das discussões realizadas em sala, ao analisar as imagens, que alguns alunos consideraram os discursos violentos como engraçados, e os risos e colocações surgiram durante a apresentação das mesmas, na qual foi pedido para eles se posicionarem e, ainda, após os estudantes rirem, foram levantadas pelos professores estagiários as seguintes indagações: "Vocês acham engraçado? Por quê? Sabem que violências naturalizadas não são consideradas violências?". Os grupos de estudante que acharam graça tentaram justificar seu riso: "Mas precisava usar este vestido?", "Mas não podia escolher um lugar melhor para tirar foto?", "Ah, mas todo mundo já fez isso?". Entretanto, após se arguirem, silenciaram-se, às vezes, envergonhados e conscientes do discurso violento.

Ao perceber o fazer graça e chacota diante da dor do outro, vimos que alguns estudantes que participavam da oficina agiram com indiferença, não conseguiram transpor-se ao lugar do outro, não apresentaram empatia para aqueles que sofreram ou se identificaram com as vítimas de tais discursos (TIBURI, 2016). Esta graça, que naturaliza estes discursos que por si só são violentos, fundamenta a banalização de outros tipos de violência dentro da escola.

Ao analisarmos as imagens e ao iniciarmos com as discussões sobre as mesmas, parte dos estudantes não considerou que elas carreavam violências. Estes estudantes, que não avaliaram os efeitos de violação nas imagens, consistiam nos indivíduos que consideraram tais discursos como a uma relação de humor, mesmo quando parte dos alunos compuseram o grupo de violentados por aqueles discursos: mulheres, negros e desfavorecidos economicamente. Freire e colaboradores (2013) ressaltam que até $80,5 \%$ das pessoas não se reconhecem como vítimas e tão pouco que tais discursos são violentos, os outros 19,5\% são agressores ou observadores e que não percebem o incômodo que causam nos violentados, firmando-se posições de superioridade.

Durante a oficina, ressaltamos a pergunta: "Será que quem violenta se sente no direito e porquê?", e os alunos levantaram colocações como: "Tem preconceito", "Acham-se superiores", "É só para zoar". Fizemos, então, outra indagação: "Mas será que então alguns não são colocados acima dos outros relegados à condição de precariedade quando este tipo de violência acontece?", e uma aluna respondeu "Sim, é isto que fazem com as mulheres". A fim de 
manter a discussão aberta, os colocamos uma intervenção: "Então a violência mantem a posição de superioridade de alguns e de precariedade para outros"? Será que a violência não se encontra associada a nosso sistema atual do que é normal? Por que os heterossexuais não apanham por esta orientação sexual e afetiva, mas os LGBTs apanham por orientações sexuais ou afetivas diferenciadas? Por que os homens não são violentados por serem homens, mas as mulheres sim por serem do gênero feminino? Por que nas imagens zoam classes menos favorecidas e não as mais favorecidas economicamente? Por que negros sofrem racismo nas redes e pessoas caucasianas não? Com estas perguntas, um silêncio perdurou na sala.

Com a utilização da Figura 1, observamos que existiam alunos com características identitárias semelhantes ao jovem e a jovem da foto, mas os estudantes não se reconheceram como vítimas de piadas semelhantes, visto o caráter simbólico da violência já banalizada. Assim, podemos afirmar que em meio às naturalizações violentas, quem não se reconhece como vítima não reage ao discurso dominante.

Vale ressaltar que o não reconhecimento do discurso violento atrela-se à naturalização dos enunciados de dominância e contribui para que a regulamentação e a fiscalização das práticas de violação, discriminação e preconceito sejam sucintas, sutis e auxiliares da não percepção das violências no campo da escola, instaurando aí o que Bourdieu (1999) denomimou de violência de violência simbólica. Os alunos que reconheceram as violações e compreenderam que tais enunciados foram construídos e sustentados a fim de manter os regimes de verdade e as relações de dominância, apresentaram também traços de corpos precarizados e/ou envolvidos com discussões sociais em suas redes de relações. Alunas mulheres, alunos homossexuais, negros, alunos com corpos considerados obesos que, num plano mais cotidiano, configuram-se como vítimas de comentários maldosos, assédios, chacotas, piadas, deturpações e agressões sutis ou físicas.

Os padrões de violências que foram elencados pelos estudantes foram aqueles referentes aos que são direcionados as pessoas negras, mulheres, pobres, deficientes, gays, lésbicas, travestis, bregas, analfabetas, funkeiras e gordas (Figura 2). Enfatizamos que a dimensão dos violares percebidas e pontuadas pelos alunos abrangeram mais os corpos que são precarizados pelos regimes de verdade atuais, que definem um estado de normalidade baseado no indivíduo branco, heterossexual, cristão, cisgênero e pertencente à classe média. Estas pontuações nos permitiram levantar a discussão: pedagogia do diferente $\mathrm{x}$ pedagogia da diferença. É evidente que os estudantes partiram de uma óptica de que se existe o comum, o natural que tende a ser o considerado o normal e que indivíduos que fogem deste padrão de normalidade são considerados como desvio. Em contraponto, catalisamos o pensar de que existem diferentes modos de ser, que a norma é inventada, e que o enunciado se afinca como verdade na instância onde é produzido, ou seja, sustentando o discurso dominante conformado na norma.

Hall (2002) elenca a elaboração de uma identidade cultural que atua na reinvenção das diferenças como estrutura de poder cultural e tenta homogeneizar os corpos, identidades e culturas, muitas vezes, de forma impositiva e violenta. Perguntamos aos estudantes, então, se a permissão da circulação de discursos violentos se vincula à manutenção dos espaços onde os 
corpos são inseridos e colocados, no caso do humor cibernético, como corpos que ocupam espaços 'inferiores'.

Não podemos deixar aqui de ressaltar que: os discursos que carreiam consigo violências e são aportados em uma política de ódio pautam-se em imagens estereotipadas e são reproduções ideológicas frente às imagens dos sujeitos, assim, considerando também que a indignação da violência é seletiva (TOGNETTA, BOZZA 2010), alguns grupos tornam-se então mais propensos a violência do que outros (TUDIN 2008).

A naturalização das violências, via veículos midiáticos de discursos, relaciona-se a reprodução destes aos modos de ser no colégio (SALTZTRAGER, LAUREANO 2012), e também à espetacularização das violências na escola, em seu extra muros e nas redes (LIMA 2014). Entretanto, não podemos deixar de ressaltar que dentro das produções de significados se veem também as assimetrias de seus efeitos (SALTZTRAGER, LAUREANO 2012) e as possibilidades de tracionar as relações de poder.

\section{Discursos em redes e seus efeitos}

O emergir de novas identidades, que clamam por vozes nos (cyber)espaços, faz com que grupos privilegiados e embebidos em preconceitos sociais reajam violentamente (WEEKS, 2015). Na oficina, focamo-nos em problematizar estes discursos de violação, por isso a escolha da seleção de páginas consideradas de humor imersas em preconceitos de classe, raça/etnia, gênero e diversidade sexual. Foi este humor que carrega violências simbólicas que trouxemos para discutir o (cyber)espaço também como território de resistência.

É notório que os distintos olhares para as diferenças não são apagados com as comunicações dos (cyber)espaços, na verdade estes são potencializadas, visto que agora os corpos que não falavam passaram a ter desse direito (SILVEIRA 2010), e se veem as reconfigurações de significados e seus feitos. Engendra-se a possibilidade de narrar sobre si, circunscrever-se, dar continuidades (ROSA 2011), elencar as diferentes possibilidades de ser e de estar, e de perceber que tais corpos também falam. As redes mostram-se agora como espaços de produção identitária e de subjetividades, os corpos se inserem em tais discussões (CAMOZZATO, GARBIN 2010), mas como são enfrentados os discursos contra estes corpos 'diferentes'?

Nossa preocupação acerca do desdobramento destes discursos e a nossa inquietude em saber "como os estudantes se posicionariam frente aos discursos violentos nas redes" foram os impulsionadores do sendo momento da oficina. Este intervalo consistiu em relacionar as características sorteadas, que comporiam uma identidade ficcional, com uma história construída pelos estudantes e a construção de modo de olhar o mundo. A elaboração de um personagem esteve relacionada à inserção de seus criadores, de maneira que esses transpassem suas subjetividades na elaboração do mesmo e com o intuito 
em sua maioria, não se pronunciariam frente ao discurso violento na rede, visto que: a) muitos observadores não se posicionam por entenderem que a violência não é para com eles (FREIRE et al. 2013); b) que existem as naturalizações das violências simbólicas (BOURDIEU 1999); e/ou c) que se desconhece que as legislações punem os discursos violentos das redes (SILVEIRA 2010). Tais posições, que se avolumam em críticas de condutas, nortearam a dinâmica da construção e ficaram evidentes em respostas como "meu personagem é negro e esta violência é contra mulher", "o nosso personagem não vê isso como violência", "está na internet né, eles acham que é liberdade de expressão, não tem como prender eles". De uma forma geral, essas são inclinações pouco empáticas para com o Outro, ou, ainda, enfatizam a crença de que a internet é um espaço sem lei, um lugar virtual deslocado do plano material-real.

Assim, a fim de colocar em cena a ideia de internet como um lugar, uma instituição que produz sujeitos e tem efeitos sobre estes, fizemos um paralelo com a percepção dos estudantes com a instituição social escola, reconhecida como um âmbito de controle, pontuando: "olha como em todo lugar tem câmeras e bem no caminho que os alunos andam", "tem câmera que não funciona, mas mesmo assim não sabemos quais são", "olha a organização da sala, é para o professor ver todo mundo", "a gente tem hora para sair e hora para entrar", "só podemos discutir a parte que está no livro", "A escola parece uma prisão", "tem por bloco uma coordenação pedagógica". É sob este molde de vigília e panóptico, na qual o trânsito dos corpos e possibilidades de saberes são mediados, que a instituição escola produz os sujeitos (FOUCAULT 2014a).

Neste momento da oficina, voltado a um olhar apurado para as violências simbólicas, os estudantes reconheceram que tal organização já conferia uma conformação violenta, entretanto, não consideraram que cartazes de grupos de oração cristã as quartas e dispostos no corredor poderiam violar alguém. Perceberam que se tratava do ethos cristão instaurado, e os que se incomodassem por ele seriam culpabilizados por não comprendê-lo (SILVA 2013).

Quanto ao posicionamento dos personagens, os alunos, em sua maioria, não se manifestaram diante dos comentários por algumas questões como: a) as violências não eram direcionadas às suas características, ou seja, os estudantes interpretaram o personagem com composto de uma única característica, essencialista, que moldava e direcionava este apenas por si; b) o não se posicionar dava-se por um não reconhecimento, ou seja, não via o outro como um indivíduo precarizado.

Vale destacar que as apresentações das histórias e posicionamentos dos personagens surgiram de formas diversas, alguns grupos apenas leram, outros contaram sem ao menos olhar no papel; alguns apresentaram em forma de teatro. Desta forma, conseguimos alcançar o objetivo de que os estudantes utilizassem de RPG ou ST. Contudo, encontramos duas dificuldades: a) quando acabava a apresentação do personagem e se abria para os outros estudantes perguntarem, houve pouca participação, sendo assim necessário que nós, professores estagiários, perguntássemos mais nas primeiras situações, todavia, após esta quebra da timidez e com o entendimento na dinâmica, a atividade prosseguiu mais seguramente; e, b) quando indagados, os grupos não conseguiram incorporar o personagem para responder sobre violências em outras identidades, e, sim, voltaram-se à sua própria identidade para dar a resposta, de modo que a ideia de fomentar o colocar-se no lugar do Outro 
mostrou-se uma tarefa árdua, o que nos fez perceber que seria preciso mais encontros para possibilitar sua efetividade. Não obstante, a provocação já atendeu ao objetivo da oficina.

Os estudantes foram questionados se responderiam ou não aos comentários em que seus personagens esbarraram e tinham que lidar; levantaram que sim, responderiam aos mesmos. Questionários do tipo: "Eles vêm do exterior para tirar os empregos dos pais", "Isso não é normal", "Isso sempre será um pecado", entre outros. Logo vimos um conflito entre o dizer e fazer, visto que, a elaboração dos personagens foram carregadas de representações estereotipadas sobre as categorias que retiraram, tais como: etnia, orientação sexual, territorialidade, entre outros, e, ao mesmo tempo, quando iam responder os comentários, os estudantes colocavam a sua história, hibridizando-se com a obra ficcional. Contudo, a possibilidade de se deslocar ao local de outrem e de decodificar como os discursos chegaram ao espaço de produção de significados e efeitos destes mostraram-se como estratégias para começarmos a catalisar as conversas sobre quais discursos estamos veiculando nas redes.

Não temos, aqui, a ideia de fechar tal discussão, mas de levantá-la quanto às questões de representatividades, veiculações discursivas e o cuidado de si e do Outro durante o ato de se narrar e ou experimentar a alteridade, quer seja ela do corpo ou do pertencimento identitário. Neste sentido, valemos do papel da escola a fim de compreender a multiplicidade de identidades que se agrupam neste local. Os alunos trazem saberes que marcam suas identidades e características de outas instituições sociais: bairro, religião, família, internet. Cada enunciado traz marcas discursivas do local onde ele fora criado, as microculturas locais. É neste sentido que vemos a possibilidade do 'chão da escola' como um espaço para discussões que considerem outros saberes culturais a fim de levantarmos reflexões sobre os regimes de verdade apoiados por esses, e com o intuito de problematizar quem são os privilegiados ou os precarizados nas relações de 'violações' veiculadas nos cyberespaços e também dentro dos muros escolares.

\section{Considerações finais}

É evidente no percurso de nossa formação inicial e do estágio a importância de aberturas de espaço para se pensar formas diferenciadas de trabalho, a flexibilidade dos profissionais que perpassam o caminho do licenciando e os encaminhamentos que se intersectam com questões culturais. Demarcamos nossa experiência, considerando sua importância para nossa formação humana e dos alunos com quem tivemos contato.

Propusemos o uso de imagens das redes sociais e a abertura para discussões com o intuito de afinar o olhar dos estudantes para (re)pensar os discursos que circundam a escola como não inocentes. Intentamos levantar críticas ao que, antes, era considerado humor pelos estudantes, fossem na forma de frases ou mesmo de imagens veiculadas nas redes ou no próprio interior da escola. A construção dos personagens, de suas histórias, por meio de RPG e ST foram estratégias para pensar a si e para pensar no outro. Nestas estratégias há 
possibilidades de mobilizar subjetividades, de falar o que falaria um personagem fictício e permitir, através da problematização das dinâmicas, a percepção das condutas e das violações presentes nos discursos.

Observamos, durante a criação dos personagens, a dificuldade dos estudantes para discutir questões étnica/raciais, de classe, de regionalidade, de gênero e sexualidade. Ao se colocar no lugar d'Outro, que muitas vezes desconhece, os alunos tem a possibilidade de desconstruir as práticas e os discursos violentos, de se desacomodarem em relação às naturalizações de posturas, falas e ações, de perceberem que há uma diversidade cultural na escola e que os padrões, fixados também pelas piadas, são normas construídas como verdades e que invizibilizam os diferentes. Priorizamos não pensar os corpos como uma expansão do arcabouço biológico, mas, sim, em seus constructos sociais e interacionais. Neste sentido, a internet mostra-se mais ainda como uma expansão das tecnologias corpóreas e passa a compor uma identidade de gênero, a delinear um pertencimento étnico e a fazer parte das trajetórias das pessoas e a inscrever marcas positivas ou negativas em seus corpos.

Esta prática nos foi marcante, visto que permitiu refletir sobre nós mesmos, os outros, os estudantes, as violências, o papel de nossa formação e os múltiplos saberes culturais que atravessam o espaço escolar. Ao se deslocar o ensino de Biologia de seu foco conteúdista, abriu-se um espaço de discussões que se agrega às dinâmicas sociais. Neste sentido, a internet não só auxilia na composição das explicações específicas da disciplina, como possibilita que, concomitante à aula, as culturas do cyberespaço adentrem nas discussões escolares.

É certo que professores e alunos necessitam aprender a lidar com os saberes difundidos pelo (cyber)espaço e os efeitos dele decorrentes, como também se é preciso romper com os conhecimentos hegemônicos dentro da escola.

São através de nossos registros e desta prática compartilhada que gostaríamos de incitar aos outros licenciandos e professores em formação a se valerem de nossas indagações e das dinâmicas aqui pontuadas. Nosso intuito foi o de repensar as atividades convencionais de estágio e as dinâmicas de sala de aula para se trazer novas formas de abordar o ensino de Biologia e suas intersecções culturais. 


\title{
DISCOURSE, VIOLENCE AND SENSITIZATIONS ANTI- CYBERBULLYING: WE, THE OTHERS AND REAL VIRTUALITY
}

\begin{abstract}
This paper presents some of our experiences and reflections during the Supervised Internship for Teaching in Biology, especially regarding anti-bullying awareness held at the workshop "Cyberbullying: Are We Violent?". The activity took place with two second-year high school classes from a central school in the municipality of Maringá (PR). Each workshop lasted four hours, encompassing critical discussions on topics such as the social network of Facebook, sites or web pages considered as humor, and elaborating on characters and their stories in order to discuss problems related to bullying and to put themselves in the place of the Other. Among students' problematizations and narratives, we then proposed (re) thinking about the discourses that surround them, their meanings, effects and the crosses in the construction, ways of being and being in the world.
\end{abstract}

KEYWORDS: (Cyber)bullying. Subjectivities. Teaching in Biology. Awareness. 


\section{NOTAS}

1 Bananal. Disponível em: <https://www.facebook.com/Bananal1417020555231470>. Acesso em 10 de agosto de 2015

2 Anti-modinha

2.0.

Disponível

em:

<https://www.facebook.com/NewAntiModinha2.0>. Acesso em 15 de julho de 2015

3 Çidorf. Disponível em: <https://www.facebook.com/Cidorfi.Oficial/>. Acesso em 15 de julho de 2015

\section{REFERÊNCIAS}

ARAÚJO, R.M.; RAMALHO, G.L. Narrativas de Jogos Digitais: Lições do RPG de Mesa. In Anais SBGames, Universidade Federal de Pernambuco, 2009. Disponível em: $<$ http://www.sbgames.org/papers/sbgames06/27.pdf> Acesso em: 22 maio 2016.

BARROS, J.P.P. Violência infanto-juvenil e o território da escola: o Bullying como analisador de processos de subjetivação contemporâneos. Tese (Doutorado em Educação Brasileira). Universidade Federal do Ceará. Fortaleza, 2014

BRASIL. Lei 18.118 de 24 de junho de 2014. Diário oficial $n$ o 9233, 2014

$\begin{array}{cccc} & \text { Supremo Tribunal de Justiça. Justiça usa código penal para } \\ \text { combater } & \begin{array}{c}\text { crimes } \\ \text { cibernéticos. }\end{array} 2009 . & \text { Disponível } & \text { em: }\end{array}$
<http://stj.jusbrasil.com.br/noticias/234770/justica-usa-codigo-penal-paracombater-crime-virtual>. Acesso em 18 de abril de 2016

BOURDIEU, P. A dominação masculina. Rio de Janeiro: Bertrand Brasil, 1999

CAMOZZATO, V.; GARBIN, E. Corpos 'gordos' no Orkut: escritas sobre si e os 'outros'. In: COUTO, E.; ROCHA, T.B. (Org.) A vida no Orkut: narrativas e aprendizagens nas redes sociais. Salvador: Ed. EDUFBA, 2010. p. 189.

FOUCAULT, M. A ordem do discurso: aula inaugural no College de France, pronunciada em 2 de dezembro de 1970. 24. ed. São Paulo: Edições Loyola, 2014b

. História da sexualidade I: A vontade de saber. 17.ed. Rio de Janeiro:

Graal, 1988 
FREIRE, I.; ALVES, M.M.; BREIA, A.P.; CONCEIÇÃO, D.; FRAGOSO, L. Cyberbullying e Ambiente escolar: um estudo exploratório e colaborativo entre a escola e a Universidade. Revista portuguesa de pedagogia, n. 47, v.2, p. 43-64, 2013.

GUIMARÃES, L.B.; SILVA, B.L. Planejamentos de ensino entremeando biologia e cultura. Ensino em Re-Vista, n. 16, v. 1, p.33-45, 2009. Disponível em: <http://www2.fe.usp.br/ gpef/teses/agenda_2011_03.pdf>. Acesso em: 21 de set. de 2016

GUIMARÃES, D.S.; SIMÃO, L.M. Intersubjetividade e desejo nas relações sociais: o caso dos jogos nas representações de papeis. Interações, p. 30-54, 2007. Disponível em: < http://revistas.rcaap.pt/interaccoes/article/viewFile/344/299>. Acesso em: 15 de novembro de 2016

HALL, S.H. A identidade cultural na pós-modernidade. Rio de Janeiro: DP\&A, 2002

LEVY, P. Cibercultura. Trad. Carlos Irineu da Costa. São Paulo: Editora 34, 1999.

LIMA, R. Das incivilidades do dia a dia às violências nos estabelecimentos de ensino: calibragem dos termos usados e seus efeitos. In: VERALDO, I. Tensões no espaço escolar: violências, bullying, indisciplina e homofobia. Maringá: Eduem, 2014

LIMA, M.S.L.; PIMENTA, S.G. Estágio e docência: diferentes concepções. Poíesis Pedagógica, v. 3, n. 3 e 4, p. 5-24, 2006. Disponível em: $<$ http://www.cead.ufla.br/portal/wp-

content/uploads/2013/10/Arquivo_referente_ao_Anexo_V_do_Edital_CEAD_06_ 2013.pdf>. Acesso em: 11 de janeiro de 2016

PEREIRA, D.T.S.; ALVES, E. O cyberbullying no contexto escolar e os desafios para promoção de uma cultura de paz. Revista renote - Novas tecnologias na educação, n. 13, v. 2, p.1-12, 2015. Disponível em: <http://seer.ufrgs.br/index.php/renote/article/viewFile/61451/36337 >. Acesso em: 21 de setembro de 2016

PRADOS, M.A.H. Menores y riesgos en la Red. Un dilema para los padres. Anais III Congresso on line- Observatorio para la Cibersociedad. 2006

ROCHA, T.B. Scr@ps de ódio no orkut: cyberbullying, contextos e ressonâncias da violência virtual que atinge o professor. Tese (Doutorado em Educação). Universidade Federal da Bahia. Salvador, 2010. 
ROSA, N.B.K. O uso da internet como espaço terapêutico. Cadernos do Aplicação, n. 24, v.2, p.131-143, 2011. Disponível em: <http://seer.ufrgs.br/index.php/CadernosdoAplicacao/article/view/34795/23005 >. Acesso em: 22 de setembro de 2016

SALZTRAGER, R.; LAUREANO, P. Uma reflexão critica sobre o problema da violência nas escolas. Revista digital AdVerbum, n. 7, v. 1, p.50-59, 2012. Disponivel em:<http://docplayer.com.br/8528984-Uma-reflexao-critica-sobre-oproblema-da-violencia-nas-escolas-a-critical-inquiry-concerning-the-problem-ofviolence-in-schools.html>. Acesso em: 22 de setembro de 2016

SANTOMÉ, F.T. As culturas negadas e silenciadas no currículo. In: SILVA, T.T. (Org.) Alienígenas em sala de aula: Uma introdução aos estudos culturais em educação. 11 ed. Petrópolis - RJ: Vozes, 2013

SANTOS, L.H.S. A Biologia tem uma história que não é natural. In: COSTA, M.V. (Org.). Estudos culturais em educação: mídia, arquitetura, brinquedo, biologia, literatura, cinema... Porto Alegre: UFRGS, 2000.

SILVA, A.C. Laicidade versus confessionalismo na escola publica: Um estudo em Nova Iguaçu (RJ). Dissertação (Mestrado em Educação). Universidade Federal do Rio de Janeiro, Rio de Janeiro, 2013

SILVA, T.T. Alienígenas na sala de aula: Uma introdução aos estudos culturais em educação. 11 ed. Petrópolis, RJ: Vozes, 2013

SILVA, TT. Identidade e Diferença: a perspectiva dos Estudos Culturais. Trad. Tomaz Tadeu da Silva. 10. ed. Petrópolis, RJ: Vozes, 2011.

SILVEIRA, S.A. Ambivalências, liberdade e controle dos ciberviventes. In: SILVEIRA, S.A. (Orgs). Cidadania e redes digitais. São Paulo: Comitê Gestor da Internet no Brasil: Maracá, 2010

TIBURI, M. Como falar com um facista: reflexões sobre o cotidiano autoritário brasileiro. 5a ed. Rio de Janeiro: Record, 2016

TOGNETTA, L.R.; BOZZA, Thais Leite. Cyberbullying: quando a violência é virtual Um estudo sobre a incidência e sua relação com as representações de si em adolescentes. In: GUIMARAES, Á.M.; PACHECO E ZAN, D. D. Anais do I Seminário Violar: Problematizando juventudes na contemporaneidade. Campinas, SP: FE/UNICAMP, 2010. Disponível em: < http://www.pjpp.sp.gov.br/wpcontent/uploads/2013/12/53.pdf>. Acesso em: 20 de setembro de 2016 
TUDIN, C. F. Violências nas escolas e territórios educativos. In: BONAMIGO, I. S.; TORDIN, C. F; BRUXEL, K. (Orgs) As práticas da psicologia social com(o) movimento de resistência e criação. Porto Alegre: ABRAPSO SUL, 2008.

WEEKS, J. O corpo e a sexualidade. In: LOURO, G.L. (Orgs) O corpo educado: pedagogia da sexualidade. 3 ed. Belo Horizonte: Autentica, 2015. P. 35-82

Recebido: 2016-12-10

Aprovado: 2017-04-10

DOI: $10.3895 /$ rbect.v10n3.5145

Como citar:

POLIZEL, A. L.; MENDES, N. A.; CARVALHO, F. A.. Discursos, violências e sensibilizações anti-

cyberbullying: nós, os outros e as virtualidades reais. Revista Brasileira de Ensino de Ciência e

Tecnologia v 10, n. 3, 2017. Disponível em: <https://periodicos utfpr edu br/rbect/article/view/5145> Acesso em: $X X X X X X X$

Correspondência: Alexandre Luiz Polizel - alexandre_polizel@hotmail.com

Direito autoral: Este artigo está licenciado sob os termos da Licença Creative Commons-Atribuição 4.0

Internacional. 